lessons, the Research Committee will conduct another survey of the 100 practices to measure change in PCMH features.

The STFM Clerkship Medical Home Initiative adds the critical missing element in the pipeline of active national projects for the future of family medicine: the STFM FutureFamilyDocs program for premedical student recruitment, the Association of Family Medicine Residency Directors and American Board of Family Medicine $\mathrm{P}^{4}$ Project for residency education, and the AAFP TransforMED project for practice transformation. The increasing sizes of US medical school classes is an opportunity to enhance recruitment to family medicine, but it is essential that family medicine clerkships provide students with clinical experiences in PCMHs so the students can appreciate this model of practice and make informed choices about specialty selection. This national clerkship initiative will provide important knowledge about effective interventions but also can be a catalyst to accelerate the change that is necessary. Other organizations in the family of family medicine have stepped up with their national projects; STFM is now doing the same.

Jobn C. Rogers, MD, MPH, MEd STFM President

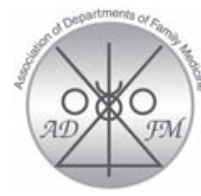

From the Association of Departments of Family Medicine

Ann Fam Med 2008;6:179-180. DOI: 10.1370/afm.827.

\section{YOU HAVE TO BE IN TO WIN: PRESENTING FAMILY MEDICINE'S PERSPECTIVE IN NIH SCIENTIFIC REVIEWS}

Science and investigation are core activities in family medicine. Katerndahl reminds us: "As with Will Pickles, Edward Jenner, James MacKenzie, and Curtis Hames, we are part of a greater quest ... we have a duty to question, to investigate, to increase our depth of understanding."1 In the United States, the largest and most prestigious source of research funding comes from the National Institutes of Health (NIH). At the NIH, decisions about funding are done after an initial scientific review, but few family medicine researchers participate in scientific reviews (less than $1 \%$ of all study section members), and if we are not in the game, we can't win.

Scientific reviews are conducted by standing and ad-hoc study section members. Each application is assigned 2 to 3 reviewers who write comments on the significance, approach, innovation, investigators, and environment of each proposed project. Although all applicants receive written comments, frequently less than one-half of the applications are discussed by the entire review group, which consists of 15 to 20 reviewers. Only applications discussed by the entire group receive a score of scientific merit. However, any study section member could request that a particular proposal be discussed and thus scored.

A working group of the advisory committee to $\mathrm{NIH}$ director Elias A. Zerhouni recently released recommendations to improve peer review and grant making. Among them is more emphasis on the potential to advance science and medical care and less emphasis on the fine points of a study's methodology. ${ }^{2}$ As family medicine researchers we can provide an important perspective on the potential impact of proposals to advance science and health care because of our grounded knowledge of what is needed by our patients and communities. This commentary provides guidance for chairs and other family medicine (FM) leaders on ways to maximize our voice in the scientific review at NIH.

What support is needed for FM faculty to participate in study sections? Faculty who participate in $\mathrm{NIH}$ study sections need release time from other academic and clinic activities. This is a critical role that would greatly benefit our discipline's reach and influence. FM leaders must understand that preparing reviews requires 5 to 6 hours per review ahead of scheduled meetings. Participants may have up to 10 grants to review per session. We must support this participation, even in the face of limited resources. The return on investment of study section participation may be measured in terms of exposure to advanced methods, awareness of potential pitfalls in future research proposals, ability to be exposed to successfully written proposals, and networking with other researchers. It is reasonable to expect that faculty members' participation be contingent on their ability to produce grant proposals after participation and that continual support for participation be tied to individual, research group or departmental success in grant funding.

What skills are needed for the potential study section member? They need to have additional training or experience in scientific methodology, either quantitative or qualitative methods, and content expertise in an area demonstrated by publications in the area of research interest. Part of the scientific review process is the ability to be effective in a group setting. The faculty member needs to have familiarity with potential biases and limitations but also needs to be able to articulate the benefits of particular approaches despite some limitations. Study section members need to understand that they have an advocacy role as well as a scientific one. Study section members must translate for colleagues of 
other disciplines the potential benefits of the proposed studies and be able to articulate "this is the best we have in the field" (if indeed this is the case) and defend overly critical exercises in tearing projects down.

How do we prepare the next group of FM researchers to be study section members for NIH? Preparing faculty for participation in study sections is a critical faculty development need and opportunity. ADFM needs to partner with NAPCRG and STFM, as well as the CTSA programs, in preparing faculty for these tasks. The limited orientation sessions prepared by the Scientific Review Administrators are not enough. We feel that those family medicine researchers who have study section experience should share experiences with other family medicine researchers so that the learning curve can be accelerated for the benefit of the applications being considered. ADFM is supporting a lecture-discussion during the upcoming STFM meeting in Baltimore entitled "How To Be an Effective Study Section Member!" It is important that we demystify the process and mitigate the fear that sometimes inhibits participation.

Current changes in NIH that emphasize translation, implementation, and dissemination represent an excellent opportunity to fund innovative, integrative, multidisciplinary studies that have a FM perspective that will benefit the patients and communities we serve, but we have to be in to win.

\section{Carlos Roberto Jaén, MD, PbD \\ Paul James, MD, and the ADFM}

\section{REFERENCES}

1. Katerndahl DA. Directing Research in Primary Care. Oxford: Radcliffe Publishing; 2006:31-32.

2. National Institutes of Health. Enhancing Peer Review. http://enhancing-peer-review.nih.gov/index.html. Accessed Dec 15, 2007.

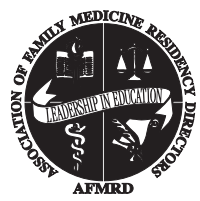

From the Association of Family Medicine Residency Directors

Ann Fam Med 2008;6:180-181. DOI: 10.1370/afm.826.

\section{TITLE VII: REVISITING AN OPPORTUNITY}

Through the Health Resources and Services Administration (HRSA), the Title VII (Section 747) Program is an opportunity for residency programs in family medicine to obtain additional financial resources. Specifically, the announcement for this program provides an excellent summary:
The Primary Care Medicine and Dentistry Programs provide grants to public or nonprofit private hospitals, schools of medicine, osteopathic medicine, dentistry, physician assistants and other public or private nonprofit entities that prepare primary care physicians through predoctoral education, residency training, faculty development, and establishment or substantial expansion of academic administrative units. ... Funds are also provided for cooperative agreements and contracts to develop, implement and disseminate innovative curriculum.

Henderson and Scanlon point out that practitioners who spend part of their training providing care for the underserved are 3 to 10 times more likely to practice in underserved areas. ${ }^{2}$ Medical schools that received Title VII grants during the last 16 years produced twice as many family physicians as schools that did not receive funds. ${ }^{3}$ As of September 2004, over a 25 -year history of the program, 438,000 predoctoral students and 64,000 residents in family medicine, 36,000 residents in general internal medicine and pediatrics, 40,000 physician faculty, 4,500 dental residents, and 61,000 physicians assistants have been trained. ${ }^{4}$

Title VII grants serve as an additional funding source to accomplish many goals including curricular innovation. Early successes included curricular development in geriatrics, family-centered maternity care, sports medicine, third-year family medicine clerkships, rural health, fellowship training, and community-oriented primary care aimed at vulnerable populations affected by HIV, family violence, chronic disease, mental illness, and multicultural issues. Newer areas of creativity include e-commerce for the clinical office, genetics, and innovation spurred by the Future of Family Medicine. According to Freeman and Kruse, "These grants are the foundation for programs that train academic leaders of the future who are more likely to instill in their students an understanding of the importance of personal medical homes and a sense of obligation to serve communities and populations. ${ }^{15}$ For fiscal year 2007, more than 55 awards totaling nearly $\$ 7.9$ million were provided to family medicine residency training programs in 28 states.

As noted by Carlisle, a majority of communitybased residency programs do not receive Title VII funding. ${ }^{6}$ Since community-based residency programs comprise more than $85 \%$ of family medicine residency programs, efforts should be developed to encourage these programs to better take advantage of this funding opportunity. Especially important for these residencies are the possibilities of getting funding for research infrastructure such as contracted research assistants for design and project implementation or contracted statisticians for data management.

Each year, Title VII funds have been under assault. 